\title{
El problema de la paz en Kant*
}

\section{Antonio Hermosa Andújar**}

\section{RESUMEN}

En el mundo de la razón práctica, tal y como Kant lo concibe, no cabe la discontinuidad entre teoría y práctica de los ámbitos de la moral, el derecho y la política. La moral se constituye en teoria del derecho y éste tanto en práctica de la moral como en teoría de la política. La política es, a su vez, la práctica del derecho. El concepto de deber es el núcleo que articula la continuidad de sus partes.

En Sobre la paz perpetua, Kant traslada sus convicciones a la esfera de las relaciones internacionales. Empero, su esfuerzo se salda con un fracaso general, porque no da ninguna garantía de que la unión de moralidad e interés o fuerza, en cualesquiera campos de la acción humana, baste para que la primera refrene el efecto de los segundos.

PALABRAS CLAVE: Kant, paz, relaciones internacionales, libertad, moralidad, guerra.

\begin{abstract}
In the world of the practical reason as Kant conceives it, no discontinuity is possible between theory and practice in each area that constitute it (moral, law and politics). The first one is based theoretically on the second one, and this one in practice on the first one and theoretically on the second one. The politics is, likewise, the practice of law. The concept of duty would be the base of the entire building and the nucleus that articulates the continuity of its parts, as a group of rules. This is what Kant aims to demonstrate in the writings studied here. Especially in "Perpetual peace", he tries to move his convictions to the area of international relations. But it is a total failure, because there is no guarantee that the union of morality and interest or force in any human action fields is enough so that the first one restrains the effect of the second ones.
\end{abstract}

KEY WORDS: Kant, peace, international relations, freedom, moral, war

\footnotetext{
* Artículo recibido el 8 de noviembre de 2016 y aceptado el 28 de febrero de 2017.

** Profesor de la Universidad de Sevilla. Director de Araucaria. Revista Iberoamericana de Filosofía, Política y Humanidades. (hermosa@us.es)
} 
El presente artículo trata sobre el ámbito de la razón práctica, incluida la filosofía de la historia. Ésta carece de presencia y tratamiento autónomos, aunque se siente fuerte su pálpito en las consideraciones relativas al establecimiento de la paz, su punto culminante.

Comenzamos en el tópico que separa la teoría de la práctica en el mundo de la acción. Con empeño militante, el filósofo de Königsberg compromete toda la potencia de su filosofía en restaurar la obligada unidad. Kant se pregunta: si en la ciencia nadie abogaría por dicha separación, ¿por qué, en la que más nos importa de todas, se niega y aun se recrean ante semejante obscenidad intelectual? Y es que, en efecto, no hay práctica que no descanse en principios universales, y la teoría es el conjunto de los mismos para cada actividad, moral incluida.

El arma de la que se valdrá Kant en una lucha que la mayoría da por perdida, y apenas él por ganada, para recomponer la unidad, es el concepto de deber. Arma poderosa, no al alcance de cualquiera, por cuanto su uso exige prescindir de las condiciones empíricas en la aplicación de la ley que lo establece. Para empuñar esta arma se requiere virtud. Esto es, fuerza y valor para superar los obstáculos a su ejercicio, en lugar de felicidad, el destino para el que nos dota la naturaleza y aparente condición del deber en la conciencia de todo soldado.

Con el concepto de deber en la mano, Kant recorre el ámbito individual de la moral y el ámbito social del derecho público, subdividido en tres escenarios. El primero es el de las relaciones interindividuales y de los individuos con la autoridad en el interior de los Estados. El segundo es el de las interrelaciones estatales entre sí. El tercero es el de las interrelaciones de los individuos pertenecientes a Estados diferentes.

En el escenario de las relaciones interindividuales y de los individuos con la autoridad en el interior de los Estados, el deber, en el sentido fuerte que aquí le atribuye Kant, carece de todo fundamento material, esto es, de toda dependencia de la felicidad. ${ }^{1}$ Por otro lado, se halla imbuido de un fin, a saber, el de coadyuvar a la "realización del bien supremo posible en el mundo". ${ }^{2}$

\footnotetext{
${ }^{1}$ Kant no expulsa la felicidad del reino de la moralidad; expulsa la posibilidad de que se convierta en el fundamento de la acción moral. La lógica de la idea reproduce la expresada por Maquiavelo en El Príncipe, aunque cambien los protagonistas. En este caso, no se expulsa a la ética del ámbito de la política, pero sí se expulsa la posibilidad de convertirla en su fundamento.

${ }^{2}$ Kant, Inmanuel, Schriften zur Anthropologie, Geschichtsphilosophie, Politik und Pädagogik, Frankfurt am Main, Suhrkamp, 1978, p. 132. [En torno al tópico: "Tal vez eso sea correcto en teoría, pero no sirve para la práctica", p. 100; en: Kant, Immanuel, Ensayos sobre la paz, el progreso y el ideal cosmopolita, Madrid, Cátedra, 2009. Ésta será la edición a partir de la cual citaremos en lo sucesivo].
} 
El deber es la observancia incondicionada categóricamente exigida por una ley incondicionada al libre albedrío de un sujeto. Gracias precisamente a la libertad de su voluntad, el sujeto se halla en grado de llevar a cabo los mandatos de aquélla, sin que a ninguna circunstancia exterior le quepa interferir en el cumplimiento de los mismos.

Para esta ley, es decir para Kant, el hecho de hallarse en pobreza extrema no es razón para que la persona que se topare accidentalmente con dinero en la calle no deba restituirlo al legítimo propietario - tal vez un rico terrateniente, causante quizá de su paupérrima condición actual, que al sacar la pitillera se le cayó azarosamente al suelo y no quiso detener su carroza para recogerlo-. Ni en ese caso puede quedarse con lo que no es suyo, ni si el cumplimiento del deber constituye una afrenta a su felicidad, sumiéndole en una orfandad natural, pues fue la naturaleza quien la prescribió para todos sus hijos.

En lugar de saludar las excepciones como una especie de refinamiento sensible que amplía la posibilidad de extensión de esa moralidad casi angelical entre los hombres, Kant completa el cuadro puro de la moralidad recordando que el individuo libre cuenta con la disposición de la voluntad para seguir la ley moral, eso que llama "sentimiento moral" y que siempre es efecto de la obediencia a la ley, nunca su causa. Tal es el juego de fuerzas que orbita en torno al concepto del deber, cuya simplicidad es defendida por su artífice frente a quienes lo tachan de ininteligible para la mayoría de los humanos, además de impracticable para la totalidad, afirmando que puesto que el hombre puede seguirlo, debe hacerlo.

No vamos a seguir profundizando el cuadro de la moralidad kantiana; el breve esbozo trazado nos permite ya hacernos una idea, cuando menos sumaria, de su significado. Al situar en el concepto de deber el núcleo de la misma, así como la garantía de la unidad entre teoría y práctica en dicho campo, Kant reconocía explícitamente su viabilidad empírica: "no sería un deber perseguir cierto efecto de nuestra voluntad si éste no fuera posible en la experiencia". ${ }^{3}$ Se trataba, pues, de una moralidad plausible, aun cuando la severidad de su contenido quedaba ahí implícitamente lacrada. Pero al sostener más tarde que "quizá nunca un hombre haya cumplido con su deber [...] de un modo absolutamente desinteresado"4 no sólo se refrenda la severidad mentada, sino que en realidad se reconoce igualmente su difícil, por no decir imposible, práctica.

\footnotetext{
${ }^{3}$ Kant, Immanuel, Ensayos sobre la paz, el progreso y el ideal cosmopolita, Madrid, Cátedra, 2009, p. 97.

${ }^{4}$ Kant, Immanuel, Ensayos sobre la paz, el progreso y el ideal cosmopolita, Madrid, Cátedra, 2009., p. 106 [las cursivas son mías].
} 
Un deber puro, desvinculado de toda mancha material aportada por el interés o la felicidad, como causa permanente de la acción moral, presupone asimismo un legislador puro - esto es la ley moral, en apariencia ajena a toda raíz teológica - y una voluntad pura. Una ley moral que a la voz autoritaria de quiero produce impenitentemente el efecto debo en la voluntad no sólo es un mundo a priori, irreconocible en el mundo real, sino por fuerza desdeñado por éste, ya que es también un mundo de esclavos. ${ }^{5}$

En efecto, en la moralidad kantiana no hay ni rastro de la conciencia, el órgano de la moralidad con el que cada sujeto tasa las máximas o reglas que inspiran su acción. Los propios actos en los que ésta se va desglosando, por diversos motivos, no siempre concuerdan con aquéllas y el aprendiz de brujo que es el hombre debe variar y equilibrar al compás de su responsabilidad.

Hay otras insuficiencias en la concepción moral kantiana que nos limitaremos tan sólo a señalar. Cuando más arriba indicábamos que al concepto de deber se fía la tarea de realizar "el bien supremo posible en el mundo" dejamos sin precisar los presupuestos que implica. Estos son, por un lado, el reconocimiento de la existencia de un ser supremo; por otro, el de la existencia de un más allá, de una vida futura. Si a todo ello sumamos la ulterior afirmación de que el cumplimiento del deber revela la presencia en el hombre de un fondo de disposiciones divinas ${ }^{6}$ sobran ingredientes para asistir al milagro de la conversión de la ética en religión. Una ética que inicia su camino en la inmanencia y lo concluye en la trascendencia es, además de una ética irreconocible como tal, la segunda gran contradicción del sistema moral kantiano. ${ }^{7}$

En Sobre el dicho común, Kant aspiraba a reconciliar, también en el reino del derecho público, la unidad entre teoría y práctica, burlonamente negada por muchos de sus contemporáneos. El concepto de deber vuelve a ser una vez más el eje de los argumentos pro unión, desplegados por su autor en el triple ámbito del Estado, las relaciones internacionales y el cosmopolitismo. Esta teoría normativa transforma el "deber primordial e incondicionado" ${ }^{8} \mathrm{de}$ constituir sociedades en el deber de organizarlas y relacionarlas mediante el derecho. Éste tiene, como en la moral, su fundamento en la libertad. Además,

\footnotetext{
${ }^{5}$ Es la máxima paradoja, y aun contradicción cabría decir, del sistema ético de Kant: concebir la libertad como obediencia, ya que la libertad de la voluntad cimenta el concepto de deber, es decir, el entero edificio de la moralidad kantiana.

${ }^{6}$ Kant, Immanuel, Ensayos sobre la paz, el progreso y el ideal cosmopolita, Madrid, Cátedra, 2009, p. 109.

${ }^{7}$ Con tal contradicción se ligaria una tercera, a saber: la conversión de la ética formal, revolucionaria según Kant, por ser la única en la historia en la que la ley moral determina incondicionadamente la libre voluntad, en ética material, como todas las demás, según el propio autor. Pero esta última cae fuera de nuestro actual objeto de estudio.

${ }^{8}$ Kant, Immanuel, Ensayos sobre la paz, el progreso y el ideal cosmopolita, Madrid, Cátedra, 2009, p. 111.
} 
esta teoría conforma el resultado final de sus esfuerzos. Mas, como las fases de su desarrollo coinciden grosso modo con las de la construcción de la paz entre los Estados, las cuales Kant detalla en el segundo texto aquí presentado, se dedica a tal cuestión el resto de este trabajo.

La instauración de la paz es problemática porque, al decir de Kant, ni la naturaleza ni la sociedad la generan automáticamente. Al contrario, lo espontáneo para ambas es segregar conflicto y guerra. De hecho, fue la guerra el motor de la civilización, ${ }^{9}$ hasta que, en la época moderna, entró en mortal contradicción con su obra.

Además de su condición social, el ser natural humano se caracteriza por la "insociable socialidad". Esto es que, al relacionarse con sus semejantes, el humano llega a un inevitable antagonismo frente a ellos. Esto ante los efectos uniformadores del instinto, que homologa a todos por abajo naturalmente -como el deber los homologa a todos por arriba, moralmente-. En cuanto seres genéricos, la pasión se yergue sobre los humanos como elemento diferenciador, que individualiza en un mundo de iguales, e induce a imponer su capricho frente a la norma común.

Mas, al dejarse arrastrar por esa moralidad, el individuo al que el instinto impulsa a la pereza, al conformismo, o a la brutalidad, a asemejarse a sus hermanos animales, da junto a los demás "los auténticos pasos desde la barbarie hasta la cultura”. Así, desarrolla con el tiempo todos sus talentos y, en el espacio, las diversas formas de civilización. Esta operación mimetiza a escala global, cuando conformando pueblos con sus vecinos más próximos, el humano intenta imponer el dominio de su propio pueblo sobre otros, magnificando el antagonismo individual en conflagración nacional.

Estas guerras profundizan y dilatan, interior y exteriormente, el proceso civilizador, el cual, sintetizado en una palabra, es la razón. De ahí que hayamos de "dar gracias a la naturaleza por la incompatibilidad, por la envidiosa vanidad que nos hace rivalizar, por el anhelo insaciable de acaparar e incluso de dominar”. Hemos de agradecer doblemente por esa transformación de la armonía y la concordia en tensión y discordia, que conducirá a la especie humana a sacar a sus miembros -seres sociales por naturaleza- del caparazón animal y desarrollarse como especie racional y moral. ${ }^{10}$

La obra civilizatoria de la guerra demuestra que la sociedad no es por sí misma el marco natural de la paz. Los pueblos que necesitan de la fuerza para

\footnotetext{
${ }^{9}$ Kant, Immanuel, Ensayos sobre la paz, el progreso y el ideal cosmopolita, Madrid, Cátedra, 2009, p. 38. Primero nos conduciría de "la barbarie a la cultura", para ir produciendo a continuación las demás conquistas civilizatorias. ${ }^{10}$ Kant, Immanuel, Ensayos sobre la paz, el progreso y el ideal cosmopolita, Madrid, Cátedra, 2009.
} 
avanzar podrán denigrar los desórdenes de la guerra, lamentar la incertidumbre de las vicisitudes que atraviesa, renegar de la violencia que arrastra y hasta maldecir su necesidad aun reconociéndola vital. Sin embargo, en ningún caso se atreverán a negar el valor civilizatorio de los efectos que produce. Sólo en nuestra época, asevera Kant, la guerra ha agotado su misión y deviene el principal enemigo, no sólo de la cultura y la paz, sino de la propia existencia. El imperativo moral exige, pues, su destrucción.

Kant concibe la realización de dicho imperativo como la tarea por antonomasia de la época ilustrada en la que vive, la condición para que el sueño del progreso ínsito en la condición humana no se convierta en una pesadilla más. Por ello, cuando afronta la misión de aniquilarlo intelectualmente lo hace con la extraordinaria potencia de su razón puesta conscientemente al servicio de la mejor causa para la humanidad. Y, justo por eso, el planteamiento, desarrollo y radicalidad de su discurso constituye una novedad histórica de importancia trascendental. ${ }^{11}$

Kant considera que la paz es posible por ser necesaria. A partir de ahí, su discurso, contemplado en perspectiva histórica, ocasiona el rechazo de la mayoría, de las posiciones anteriores o coetáneas a las suya no sólo de quienes en el mundo antiguo -Tucídides, Platón, Aristóteles, Tito Livio, entre otros- o en el mundo moderno -Maquiavelo, Hobbes, pero también Vitoria, Grocio, Locke o Vattel- la juzgan inevitable aunque no deseable.

La guerra ya no será más, por tanto, ese derecho con el que la naturaleza dota al más potente en el territorio de la anarquía constituido por las relaciones internacionales, -como los atenienses afirman inapelablemente ante los melios en el diálogo de Tucídides ${ }^{12}$ y en el que la fuerza se legitima a sí misma sin el embozo de la ideología- ni volverá a computarse entre los aliados jurídicos de la justicia -como hace Tito Livio, padre del concepto de guerra justa, ${ }^{13}$ genuino trasunto ideológico legitimador de la violencia que ejerció Roma contra sus enemigos-.

\footnotetext{
${ }^{11}$ La radicalidad, a decir verdad, está más al principio que al final de su obra, como se verá después.

${ }^{12}$ Tucidides, Historia de la Guerra del Peloponeso, Madrid, Tecnos, 2000, p. 97.

13 "La guerra [...] es justa cuando es una necesidad, y las armas legítimas para aquéllos a los que no se les deja más esperanza que las armas"; Tito LIvIo, Historia de Roma, Madrid, Gredos, 2001. Con todo, y como bien afirma Ridder (RIDDER, Helmut, "La guerra y el derecho de guerra en el derecho internacional y en la doctrina internacionalista", Revista de Estudios Políticos, núm. 92, 1957, p. 38), se trata de una teoria que "alcanza su culminación escolásticas en el siglo xilI"; Tomás de Aquino fue su mejor defensor. Esa división, añadamos, terminaría anulando Vattel en el siglo XVIII.
} 
Tampoco, dicho sea por contraste, su paz será “la paz... con todos” propugnada por Isócrates, ${ }^{14}$ pues aunque denuncia el imperialismo ateniense y declara un mal la joya más representativa del poder de la ciudad frente al exterior, el imperio, se trata de una paz que deja abierta la puerta a la guerra, como demuestra el hecho de que simultáneamente abogue por la conservación de los aliados postulando tan sólo un cambio, más igualitario, en la relación con ellos. ${ }^{15}$ En su opinión, tal circunstancia era suficiente para justificar la preservación de la hegemonía de Atenas.

Tampoco operará en lo sucesivo la distinción entre guerra justa y guerra injusta, introducida por la patrística y la escolástica en la Edad Media, que desarrollaron Vitoria y otros en la Edad Moderna. No obstante, en esa misma época, cuestionaron tal distinción pensadores que consideran la guerra un mal inevitable, como Grocio o Vattel, y otros que la consideran inevitable, por ser una función de la estructura de la sociedad internacional, como Hobbes y Locke.

De ese modo, se acabaron los debates y realidades en los cuales se legitima la guerra. Por ejemplo, en el caso de la guerra justa, la subjetivación de la justicia internacional concedía a cada Estado la facultad de ser parte, juez y órgano en la ejecución del derecho. ${ }^{16}$ Esto es un peligro de guerra permanente, dada la facilidad con la que cada Estado que decida emprender una se topará con su motivo justo, pero acarrea otro mayor: el de la supresión del ius in bello. Éste es el conjunto de normas con las que dentro de una guerra se intenta proteger al inocente, evitando el arbitrio y la secuela de sufrimiento y violencia -de las partes, mientras combaten, y del vencedor sobre el vencido-.

Se acabarían también los debates en los que se contiende sobre si la guerra es un simple acto más de la libertad natural de los Estados en una condición de anarquía o si se debe optar por juridificar dicha libertad y considerar pues el ius ad bellum como un atributo más de la soberanía estatal. ${ }^{17}$ Acabar eternamente con la guerra, instaurar la paz perpetua, como pretende Kant, es poner fin simultáneamente a los debates que acompañan su naturaleza y su ejercicio.

Instaurar la paz pasa por la supresión de las condiciones que garantizan la reproducción permanente del conflicto bélico, primero, y por un alto grado de institucionalización de la libertad después. Ello, tanto por su complejidad inte-

\footnotetext{
${ }^{14}$ IsócRATES, Discursos, Madrid, Gredos, 2002.

${ }^{15}$ Isócrates, Discursos, Madrid, Gredos, 2002..

${ }^{16}$ RidDER, HeLmUt, "La guerra y el derecho de guerra en el derecho internacional y en la doctrina internacionalista", Revista de Estudios Políticos, núm. 92, 1957Helmut Ridder, cit., p. 41.

${ }^{17}$ RIDDER, HELMUT, "La guerra y el derecho de guerra en el derecho internacional y en la doctrina internacionalista", Revista de Estudios Políticos, núm. 92, 1957, pp. 39-40.
} 
lectual como por su mayor racionalización normativa, distancia netamente a Kant de Erasmo de Rotterdam, uno de sus precursores en la aspiración al logro de una paz definitiva. ${ }^{18}$ Kant cifra su objetivo en la observación de lo que llama artículos preliminares y artículos definitivos, los cuales componen el camino conducente a la paz.

Los artículos preliminares establecen la prohibición de estipular cualquier tratado de paz "con la reserva secreta sobre alguna causa de guerra en el futuro". El contexto, innominado pero visible, es el llamado modelo Westfalia o de equilibrio de poder, ${ }^{19}$ en el cual los Estados forman alianzas cambiantes entre sí con objeto de refrenar el poder de la nueva potencia emergente e impedir su dominio en el concierto internacional. ${ }^{20}$

Dicho modelo, característico de la Europa del Antiguo Régimen, esbozado por Demóstenes, perduró hasta bien entrado el siglo xx. ${ }^{21}$ Está constituido por Estados patrimoniales, cuyos señores juegan al trueque o a la compraventa con ellos cual si se tratara de una mercancía más. Es ese capricho de soberanos lo que proscribe el segundo artículo preliminar. Tales Estados poseen ejércitos bien pertrechados en permanente rivalidad, siempre en pie de guerra.

Hoy día, estos no son sino fábricas de esclavitud y muerte para los autómatas que actualmente habitan todo Estado, al ser privados de sus derechos: a su desaparición apunta el tercero de los artículos preliminares. El mantenimiento de esos ejércitos, por otra parte, exige la continua emisión de deuda pública. La riqueza que debiera invertirse en desarrollo se destina a la modernización del ejército, con la consecuencia de un empobrecimiento general y galopante. Tal práctica es condenada por el cuarto artículo preliminar.

Los ejércitos, además, están dispuestos de continuo a intervenir en los asuntos internos de otros países, para lo cual únicamente requieren escuchar la voz del amo, cuando ningún hecho crea el derecho de injerencia a favor de ningún Estado. Contra semejante atropello, se alza la prescripción del quinto artículo preliminar. Una vez iniciado el combate, los ejércitos prestamente ol-

\footnotetext{
${ }^{18} \mathrm{Hay}$ al menos tres elementos de divergencia entre Erasmo y Kant: el modelo de este último no es teológico, no se basa en el ejemplo de Cristo; la república, el régimen de la libertad, se antepone a unas leyes de las cuales se espera que cambien las costumbres; y la federación de repúblicas, preferida al arbitraje, la negociación y la firmeza en los tratados internacionales, que son las soluciones a las que adhiere el teólogo holandés (cfr. Hermosa, Antonio, "La concepción kantiana de las relaciones internacionales", Revista de Estudios Políticos, núm. 64, 1989, p. 132).

${ }^{19}$ Kant llama "una simple quimera" a la paz derivable de este modelo de sociedad internacional (Kant, ImmAnuel, Ensayos sobre la paz, el progreso y el ideal cosmopolita, Madrid, Cátedra, 2009, p. 138).

${ }^{20}$ Kant reforzará ulteriormente este artículo preliminar con la exigencia de publicidad como un principio trascendental del derecho público. Kant, Immanuel, Ensayos sobre la paz, el progreso y el ideal cosmopolita, Madrid, Cátedra, 2009, pp. 181.

${ }^{21}$ Demóstenes, Discursos políticos, Barcelona, Ediciones Iberia, 1969, p. 22.
} 
vidan el ius in bello, el complejo normativo con el cual la civilización ha ido construyendo un derecho formal que oponer al derecho material a la guerra. Esto es, violación de la humanidad en cada persona que el sexto artículo preliminar aspira a erradicar.

Kant da cabida a ideas antropológicas, morales, jurídicas y políticas, fundamentales en el mundo que integra su concepto de razón práctica. Podemos advertir que las palabras no son inocentes. Tampoco es inocente el aumento injustificado de la potencia de un Estado (artículo 1); la presencia de la figura del contrato social originario - a pesar de la crítica demoledora a la que Hume lo había sometido-22 como símbolo jurídico en el que Kant concentra su visión del hombre como fin en sí (artículo 2), portador de la humanidad en su persona (artículos 3 y 6).

Tampoco es inocente la precaución contra el arbitrio, considerando la naturaleza humana y el poder de los soberanos (artículo 4), ni la autonomía moral de individuos y pueblos, o la relación entre ética y política (artículo 5). Finalmente, tampoco es inocente su confianza en el hombre, pues ni en la guerra pierde su humanidad, sea en condición de verdugo o en su condición de víctima (artículo 6).

Veamos ahora los artículos definitivos para la paz perpetua. La paz es mucho más que la eliminación del conflicto interestatal o que un simple armisticio, siempre provisional. Es una situación positiva, no el mero contrario de la guerra, como enseñara Hobbes. La paz es el resultado de tres causas combinadas: la república, a nivel estatal; su federación, a nivel interestatal y el cosmopolitismo. 0, si se prefiere, una determinada organización política del Estado, una determinada unión de Estados así organizados y seguridad en el exterior para los individuos de cada país. De este modo, cabe una síntesis más breve: la paz es la juridificación del conjunto de las relaciones humanas.

¿Por qué una república? La explicación está lógicamente en el qué es una república. El orden republicano es el único idealmente derivado del contrato originario, fuente normativa de la legislación de todo Estado legítimo, fundado en tres principios a priori. Esto es, "la libertad de cada miembro de la sociedad en cuanto hombre. La igualdad de éste con cualquier otro, en cuanto súbdito. La independencia de cada miembro de la comunidad, en cuanto ciudadano". ${ }^{23} \mathrm{He}$ aquí la respuesta más perentoria a la pregunta anterior, el por qué de la conexión entre constitución republicana e idea de paz.

\footnotetext{
${ }^{22}$ Hume, DaVid, Ensayos morales, politicos y literarios, Madrid, Trotta, 2011.

${ }^{23}$ Kant, Immanuel, Ensayos sobre la paz, el progreso y el ideal cosmopolita, Madrid, Cátedra, 2009, p. 112. Dicha posición será modificada precisamente en Sobre la paz perpetua.
} 
La libertad interna de cada hombre significa para Kant dos cosas, ambas explicitadas en Sobre el dicho común, pero sólo una en el texto que venimos analizando. En primer lugar, la libertad interna significa que cada uno es el mejor guía para buscar la felicidad propia, por lo cual un gobierno paternalista que pretenda imponer un único patrón para todos está fuera de orden. Son sujetos de derechos lo que un gobierno tiene enfrente, un pueblo en grado de deliberar en torno a su destino colectivo.

Un gobierno tiene enfrente a los miembros de un pueblo que han dado el salto desde su primitiva condición de esclavos a la actual de seres racionales que se atreven a pensar; no el rebaño de ovejas que eran tiempo atrás merced a una mezcla espuria de intereses religiosos y políticos, armonizados en el objetivo común de relegarlos por siempre a un estado de pupilaje. ${ }^{24}$ En segundo lugar, la libertad se manifiesta en el consentimiento que tales sujetos de derechos dan a las leyes que les gobiernan, especialmente a aquélla que declara la guerra, por cuanto son las principales víctimas de las mismas. ${ }^{25}$

La igualdad jurídica implica que todo súbdito puede imponer a cualquier otro derechos de coacción y, si bien dicha igualdad es compatible con el máximo de desigualdad en la propiedad privada, ni esto, ni la posición social, ni ninguna otra circunstancia externa, afirma Kant, da por sí misma derecho a nada a los posibles beneficiarios. Ello permite fijar en el mérito el requisito básico para el ascenso en la escala social. En lo sucesivo, al menos desde la mirada del derecho, ni un "noble" de nacimiento será por ese hecho moralmente un hombre noble, ni la nobleza moral es de su poder. ${ }^{26}$

La independencia es la igualdad de los ciudadanos en su derecho al voto, cualidad que presupone una única cualidad, a saber: "que uno sea su propio señor (sui iuris) y, por tanto, que tenga alguna propiedad”, sin importar cuánta, ni tampoco, como en Locke, cómo llegó a hacerse con ella. Tampoco aquí la desigualdad en el monto de la propiedad afecta a la igualdad jurídica entre ciudadanos, sintetizada en el lema un hombre un voto. Y tampoco aquí el terrateniente es en principio políticamente más que el artesano, en grado de procurarse su subsistencia. ${ }^{27}$

\footnotetext{
${ }^{24}$ Kant, Immanuel, Ensayos sobre la paz, el progreso y el ideal cosmopolita, Madrid, Cátedra, 2009, p. 21.

${ }^{25}$ Kant, Immanuel, Ensayos sobre la paz, el progreso y el ideal cosmopolita, Madrid, Cátedra, 2009, pp. 113-114 y 149-150.

${ }^{26}$ Kant, Immanuel, Ensayos sobre la paz, el progreso y el ideal cosmopolita, Madrid, Cátedra, 2009, pp. 113-115 y 149-50. Al lector quizá sorprenda que dos mil quinientos años después el pensamiento europeo siga debatiendo problemas y llegando a conclusiones que ya Hesiodo, nada menos, se había planteado y resuelto del mismo modo (HEsIodo, Obras y fragmentos, Madrid, Gredos, 2000). Si el propio Kant, tan revolucionario en la Prusia contemporánea, hubiera tenido presente ese dato, a su ciega fe en el ineluctable progreso de la humanidad quizá se le habrian bajado los humos. ${ }^{27}$ Kant, Immanuel, Ensayos sobre la paz, el progreso y el ideal cosmopolita, Madrid, Cátedra, 2009, pp. 117-119.
} 
Así pues, la naturaleza de la república explica su conexión inmediata con la paz. Más aun con el fin del "estado de naturaleza" interindividual que garantiza -y es el único tipo de Estado que lo hace- la solución al problema de violencia en el interior de un determinado territorio. La república constituye asimismo el modelo para poner coto a la anarquía internacional. Esta anarquía, en opinión de Kant, no sólo se identifica con el estado de naturaleza -la coexistencia de Estados separados que es en sí misma una situación de guerra-, sino incluso con un modelo de sociedad internacional unipolar. Este modelo es incluso más perverso que una situación de guerra, pues una sola potencia instaura la monarquía universal sobre la tierra. Ello restauraría la anarquía a causa de su extensión, además impondría un despotismo sin alma sobre el conjunto de los hombres. ${ }^{28}$

Una federación de repúblicas constituye, por tanto, el único modo de coadyuvar a la implantación y conservación de la paz en el mundo, impidiendo que la antigua prima donna de la sociedad internacional, la guerra, vuelva a restablecer su imperio sobre ella. Del mismo modo, impediría el retroceso del hombre civilizado a su primitivo estado de barbarie, ahora que se dan las condiciones para que por medio del derecho rija el orden acorde con su naturaleza moral.

Una federación de repúblicas, sería asimismo, la institución mediante la cual someter la barbarie política de la soberanía a la regla jurídica y, con ella, los peligros autoritarios que derivan de la creación de un absoluto político legibus solutus. Esto es, el atributo del ius ad bellum, con la transformación de los individuos en animales de carga y de sacrificio que conlleva; la erección de un trono para el puro arbitrio, ocupado por el soberano, y la perpetuación de la anarquía natural hasta la final destrucción mutua de sus miembros.

El derecho cosmopolita es la tercera fuerza puesta por el derecho público al servicio de la paz. Y es derecho, insiste Kant, en lugar de "filantropía”, porque en su base hay otro que comparte el conjunto de los habitantes del planeta: el "derecho de propiedad en común sobre la superficie de la tierra". Éste a su vez genera en cada hombre un "derecho de visita", de ir a cualquier lugar del mundo sin por ello suscitar la hostilidad de los lugareños. El contexto de este pretendido derecho es, en un contexto actual, la creciente globalización del mundo. Según Kant, hace sensible en un extremo del mismo cualquier violación de la justicia en el otro.

En dicho empequeñecimiento del planeta, el comercio constituye un medio de capital importancia y desde hace siglos ve a los europeos navegar en torno a

\footnotetext{
${ }^{28}$ Kant, Immanuel, Ensayos sobre la paz, el progreso y el ideal cosmopolita, Madrid, Cátedra, 2009, p. 167. Las Réflexions sur la monarchie universelle en Europe de Montesquieu es su más probable y directa fuente.
} 
él. Su probable fuente, Vitoria, junto con Grocio, ya había fijado jurídicamente la libertad de comercio en su intento por darle forma jurídica a la colonización española de América. ${ }^{29}$ Mientras tanto, el gran jurista de Delft la había invocado al objeto de nulificar las bulas papales, las cuales desde 1493 repartían el mundo entre españoles y portugueses. ${ }^{30}$

Si bien Kant insiste más en la dimensión jurídica que en la comercial, no cabe duda acerca de la importancia concedida al comercio, más como factor del desarrollo interno de un país ${ }^{31}$ que como vehículo unificador. Por ello, resulta pacificador del mundo, bien que sin llegar a reconocerle en este punto la importancia concedida por Montesquieu, Hume y Adam Smith. ${ }^{32}$

Cuando el derecho público haya atrapado la paz, ya no se le irá de las manos. Una vez en funcionamiento, la garantía de paz le es inherente, como en Spinoza, la idea verdadera es garantía de su propia certeza. Ahora bien, en un mundo cuya historia ha progresado mediante la guerra -bien que en su fase actual amenace su destrucción; en el que los soberanos cifran su gloria en las medallas e insignias que decoran sus uniformes militares sin importar la estela de miseria y muerte sobre la que se yerguen, y en el que la rivalidad de los Estados, es decir, la occassione de transformarla en guerra les brinda una excusa permanente para declararla-, ¿dónde encontrar la garantía de que el proyecto de construcción del derecho público devenga realidad?, ¿cómo hacer en tierra enemiga de su necesidad virtud? En suma, la paz es el efecto de la acción concordante de las tres ramas del derecho público, pero ¿cómo es posible un derecho público como el postulado en un contexto que es su antagonista natural? La problematicidad de la idea de paz, como se ve, se ha trasladado del efecto a las causas, pero la dificultad no ha cambiado de grado.

Con todo, el optimismo kantiano, su fe racional en el progreso, no habría iniciado siquiera su andadura de no haber aprehendido con anterioridad su destino. Y, así, echando mano de la historia, rápidamente encuentra garantías de diversa indole con las cuales hacerla desembocar en el lugar deseado. Todo empieza en la acción de la propia naturaleza, la genuina garante del éxito en la empresa, según Kant, pero prosigue con dos fieles aliados, como son la razón, con su parto de un concepto de derecho público a priori, y el filósofo, cuya libertad de pensamiento

\footnotetext{
${ }^{29}$ VItoRIa de, Francisco, Relección primera sobre los indios recientemente descubiertos, Madrid, Tecnos, 1998, p. 132.

${ }^{30} \mathrm{Groclo}$, Hugo, De la libertad de los mares, Madrid, Instituto de Estudios Políticos, 1979.

${ }^{31}$ Kant, Immanuel, Ensayos sobre la paz, el progreso y el ideal cosmopolita, Madrid, Cátedra, 2009, p. 144.

${ }^{32}$ Kant, en efecto, no llega nunca a atribuirle la importancia de tales grandes pensadores, pero sí alcanza a divisar un "espíritu comercial" que sacará lustre al futuro de la humanidad, KANT, ImmAnuEL, Ensayos sobre la paz, el progreso y el ideal cosmopolita, Madrid, Cátedra, 2009, p. 168.
} 
mediará para corregir las políticas ajenas a la meta prescrita. Empecemos por la naturaleza, por su finalidad.

El futuro de libertad y paz, empieza en el pasado, en la naturaleza, que será quien oficie el traspaso de poderes. Esto mediante la propia guerra y otras formas de conflicto, cuyas causas Kant buscó originariamente en la propia condición humana, caracterizada por el desgarramiento de la insociable socialidad; luego, en la estructura, tanto estatal como internacional -en el autoritarismo interno y la anarquía externa-. La naturaleza hizo avanzar al hombre por dentro, así como a la sociedad, a un precio muy alto, cierto, pero llenó de complejidad psicológica, racional, moral y técnica al primero, y de progreso a la segunda. Al punto que el espectáculo de la llegada a la situación actual casi ha hecho olvidar el precio del sufrimiento pagado por la entrada, como si el rastro de miseria y muerte, o los triunfos con los que se le ha honrado, fueran meros episodios cósmicos del desenlace de la historia.

Todo eso forma parte de lo que Kant llama finalidad natural de la naturaleza, que ésta ha hecho a su aire, sin nuestro concurso, y que sigue obrando todavía hoy, cuando de lo que se trata es de echar el cierre a esa historia e inaugurar una nueva. También hoy la naturaleza quiere, esto es, hace por nosotros con independencia de lo que los hombres quieran, de lo que requieran o de lo que hagan. Será ella, en suma, la que a fin de sujetar la violencia destructora de la humanidad, de suprimir la supremacía moral y fáctica de la guerra, la que nos fuerce a fundar el derecho público en la triple dirección indicada. Ella será así la "buena voluntad" que la voluntad humana no puede ser: o paz o destrucción, ésa es la cuestión, y ante semejante disyuntiva, la naturaleza ya ha elegido lo que debemos hacer. ${ }^{33}$

Pero la naturaleza posee asimismo una finalidad moral que apunta al mismo objetivo: la paz, bien de los pueblos, como ya dijera Píndaro, ${ }^{34}$ puesto que ninguna salvación hay en la guerra, como ya dijera Virgilio. ${ }^{35}$ Tal fin es una propiedad de nuestra época ilustrada, afirma Kant, pues antes la naturaleza obraba exclusivamente para su propio fin. ${ }^{36}$ Esto a pesar de la utilización de los mismos medios coactivos con el propósito de forzar a la voluntad humana a moverse en la citada dirección. ${ }^{37}$ Ahora, en cambio, actúa al servicio del con-

\footnotetext{
${ }^{33}$ Kant, Immanuel, Ensayos sobre la paz, el progreso y el ideal cosmopolita, Madrid, Cátedra, 2009, pp. 135-137.

${ }^{34}$ Pindaro, Obras y fragmentos, Madrid, Gredos, 2002.

35 "Nulla salus bello", Eneida, XI, v. 363.

${ }^{36}$ Kant, Immanuel, Ensayos sobre la paz, el progreso y el ideal cosmopolita, Madrid, Cátedra, 2009, p. 165.

${ }^{37} \mathrm{~A}$ decir verdad, Kant añade algunos nuevos, como la división producida por lenguas y religiones, el espíritu comercial antes aludido, el dinero.
} 
cepto de derecho público a priori hallado por la razón y, por lo tanto, cuidando en su presión de no dañar la libertad moral del hombre.

Es así como acabará instaurándose el derecho político, el derecho de gentes y el derecho cosmopolita, pese a las tendencias egoístas de los hombres, pese a los intereses privados de los gobernantes y pese a las inercias y hábitos contraídos por la historia. Ahora ya se trata meramente de un problema de "buena organización”. Esto es, se trata de saber cómo encuadrar a los hombres en un sistema de reglas e instituciones que dejen en libertad su naturaleza. Por ello, si la tarea de fundar la paz antaño se antojaba hercúlea y parecía ser el destino de un "pueblo de ángeles", ${ }^{38}$ ahora, descubiertos racionalmente los medios de llevarla a cabo y preservarla, su destino se adecua incluso a "un pueblo de demonios". ${ }^{39}$

En su cruzada por la paz, la razón es aliada de la naturaleza. Su concepción a priori de la misma será muy probablemente, piensa Kant, uno de los resortes que, incluso en el escenario donde se muestra la condición humana más despreciable, inyecte en el soberano de cada Estado la fuerza del principio jurídico y ponga ante sus ojos cómo debe ser la relación entre hombres y entre Estados. Así, conmine a dirigir sus pasos hacia ese Estado universal de los pueblos, que es posible a fuer de necesario. ${ }^{40}$ En ese proceso encontrará, además, un aliado proveniente de la sociedad, el tipo humano que la razón selecciona precisamente en ella: el filósofo.

El antiguo sabio estoico, a quien Roma le enseñó a no desentenderse de la sociedad en la que vivía, ${ }^{41}$ vuelve así a la vida pública en la modernidad. En esta época, al socaire de la consigna ilustrada, el filósofo no sólo liberará al pueblo del oscurantismo de los prejuicios y de la cumplida "venganza" que planifican contra sus cultores, ${ }^{42}$ para acto seguido ilustrarle sobre sus derechos. ${ }^{43}$ Por el contrario, gracias a su connatural apartidismo, ${ }^{44}$ llevarán la verdad a palacio sin ánimo de desobediencia y sin esperar más recompensa que la que su propio oficio les depara.

\footnotetext{
${ }^{38}$ La expresión es roussoniana, y su autor designa con ella a la república con gobierno democrático, no al Estado (república) democrático.

${ }^{39}$ Kant, Immanuel, Ensayos sobre la paz, el progreso y el ideal cosmopolita, Madrid, Cátedra, 2009, pp. 165-6.

${ }^{40}$ Kant, Immanuel, Ensayos sobre la paz, el progreso y el ideal cosmopolita, Madrid, Cátedra, 2009, p. 138.

${ }^{41}$ Marco Aurello, Meditaciones, Madrid, Gredos, 2001.

${ }^{42}$ Kant, Immanuel, Ensayos sobre la paz, el progreso y el ideal cosmopolita, Madrid, Cátedra, 2009, p. 22. En ello coinciden materialistas e idealistas.

${ }^{43}$ Kant, Immanuel, Ensayos sobre la paz, el progreso y el ideal cosmopolita, Madrid, Cátedra, 2009, p. 206.

${ }^{44}$ Kant, Immanuel, Ensayos sobre la paz, el progreso y el ideal cosmopolita, Madrid, Cátedra, 2009. Para Hume son, nada menos, el "tercer partido" de la sociedad inglesa, junto a los dos políticos tradicionales, el liberal whig y el conservador tory; y el único fiable, ciertamente.
} 
Ellos son, sin más, los voceros del pueblo ante los poderosos, los representantes de la paz entre los guerreros. Para tal misión, sólo requieren del poder el reconocimiento como derecho de la libertad de pensamiento, un bien absoluto para la sociedad reclamado ya por Spinoza ${ }^{45}$ Por otro lado, éste ni siquiera implica la superioridad del filósofo sobre el jurista en las preferencias del soberano ni, su conversión en consejeros áulicos, sabedores como son de que "la posesión del poder daña inevitablemente el libre juicio de la razón”. No hay aquí, pues, nada parecido a un intento de resucitar a Platón, sino, al máximo, un anticipo de la archiconocida tesis de Weber, expuesta en su conferencia sobre el científico. ${ }^{46}$

He ahí el conjunto de garantías que conducirán a la humanidad a la paz. Dedicaremos el resto de nuestro trabajo a explorar las posibles inconsecuencias y carencias doctrinales esbozadas en los mismos. Convenimos con Kant en que la paz es una situación positiva, un statu quo en el que los Estados se han comprometido a erradicar la violencia en sus relaciones mutuas, lo cual implica un replanteamiento de las mismas.

Mas la paz no implica, como pretendiera Kant en su catálogo de artículos preliminares, la eliminación de los conflictos, sino sólo la renuncia al uso de la fuerza en su resolución. Es decir, peor en el entender de Kant, la renuncia a la fuerza como método ordinario de hacerles frente. ${ }^{47}$ No queremos extendernos al respecto, y por ello no abordaremos aquí la doble cuestión de la sistematicidad del conjunto ni la de su conexión lógica con los artículos definitivos, de las cuales ya trató con suficiencia R. Brandt.

Pero sí urge decir que la reserva mental del recurso a la guerra que prescriben constituye un mero flatus vocis en una condición de mayor o menor anarquía internacional, y en la cual el papel de garante que debiera encarnar la ley se traslada a la voluntad de la naturaleza. Más tarde veremos dónde reside dicha voluntad, la cual coaccionaría a las diversas potencias mediante la amenaza de la destrucción recíproca. Dos guerras mundiales y un sinfín de guerras más, y un armamento cuyo poder de destrucción convertiría a los cañones de los ejércitos napoleónicos en chupetes para niños le mostrarían hoy al gran pacifista que el flechazo amoroso de la humanidad se da con la destrucción antes que con la supervivencia.

\footnotetext{
${ }^{45}$ Spinoza, Baruch, Tratado Teológico-Político, Madrid, Alianza, 1986, pp. 61 y ss.

${ }^{46}$ Kant, Immanuel, Ensayos sobre la paz, el progreso y el ideal cosmopolita, Madrid, Cátedra, 2009, p. 169. De Weber, véase la segunda conferencia de el Político y el científico, Madrid, Alianza Editorial, 1998, pp. 181-233.

${ }^{47}$ La guerra en cuanto recurso último y extraordinario ha permanecido en el articulado de las dos legislaciones universalmente válidas establecidas hasta ahora: el de la Sociedad de Naciones y el de la Carta de San Francisco. Ello aun a pesar de declarar la guerra un mal, y aun mediando entre ellas el famoso pacto Briand-Kellogg, que parecia proscribirla para siempre como si se tratara de un acto ilegal.
} 
Ello sin masoquismo de por medio; tan solo por interés o por las naturales necesidades inherentes a la existencia de una superpotencia, como bien nos ilustrara ya Tucídides. Dicha reserva, en suma, significaría la disposición de los Estados a desconocer la guerra como atributo de su soberanía, un ejercicio de prudencia, ése que sólo se produce sistemáticamente cuando otro más poderoso amenaza directamente su supervivencia. La prudencia, por lo demás, sólo durará el tiempo de la amenaza y no excluye su venganza, dado que su mira no sólo se centra en la diana de la paz.

Pasemos a su institucionalidad. Lo primero en surgir al paso era la república. La democracia, por decirlo en términos actuales, no kantianos, ${ }^{48}$ como factor de paz constituye casi uno de los dogmas del pensamiento liberal en su visión de la sociedad internacional. Esto es uno de los lugares comunes que, en la visión de sus críticos, forma parte de la leyenda. ${ }^{49}$ Las democracias jamás combaten entre sí, nos dice el dogma, que en gran medida cuenta con el apoyo -nada incondicional- de la experiencia.

No obstante, se olvida de que las democracias sí combaten contra las dictaduras, hasta llega a formar parte del código genético de algunas de ellas, y que en el caso estadounidense deviene una ideología que legitima la invasión de otro país. Difundir la democracia deviene en la consigna a través de la cual se sepultan los intereses económicos o estratégicos que militan a favor de la guerra.

Además, la república kantiana dista de ser el régimen político justo que ha instituido y salvaguardado la libertad y, por ende, la ha conectado con la paz en su interior. Si añadimos dos pinceladas más, omitidas anteriormente al bosquejar el cuadro institucional de la república, el resultado la aproximará irónicamente al monstruo tiránico al que pretendía combatir. El principio de autonomía, que establece la igualdad política entre los ciudadanos, deja fuera de la misma a la mayoría de los pobladores del país, no sólo a aquéllos que, en palabras de Kant, la naturaleza excluye por sí misma, como los niños y las mujeres, sino igualmente a todos varones que no disponen de la Befugnis de autosustento. La razón

\footnotetext{
${ }^{48}$ Kant, como prácticamente la totalidad de los politólogos del siglo xVIII, niega expresamente la identificación entre república y democracia porque de ésta mantiene la concepción clásica, en la que el pueblo en su conjunto es el soberano. Esto no sólo tiene a ojos de tales críticos la desventaja de carecer de representación -lo que también significa, de un lado, el gobierno de los necios y, de otro, su propia inviabilidad material-, como la de acumular poderes que deben estar separados a fin de que el régimen sea liberal.

${ }^{49}$ Cfr. Peñas, Francisco Javier, Hermanos y enemigos. Liberalismo y relaciones internacionales, Madrid, Universidad Autónoma de Madrid, 2003. En relación con la teoría del Estado, prácticamente nunca creyeron en ella ni siquiera sus más encarnizados defensores. Asi se advierte leyendo a un cuasi gigante como Locke, o a gigantes auténticos como Montesquieu o los autores de El Federalista. De ahi que ya Loewenstein la considerara un "mito", y se admirara de la insistencia en su vigencia, en su Teoría de la Constitución, en la que le dedica un apartado mínimo a esta problemática. Loewenstein, KaRL, Teoría de la Constitución, Barcelona, Ariel, 1976.
} 
no es menos significativa que la conclusión, pues, al tener que trabajar para otros, con objeto de sobrevivir, deben asimismo adquirir la voluntad de sus amos.

Con otras palabras: la igualdad política entre ciudadanos es la violación directa de la doble igualdad anterior, la del hombre en cuanto miembro de la humanidad y la del súbdito frente a la ley. Cómo individuos iguales en su condición de hombres y de súbditos puedan devenir desiguales en relación con el poder es un misterio que ningún pietista político podrá jamás resolver, al tiempo que uno de esos secretos con los que la teoría se metamorfosea en una forma espuria de teología.

El segundo rasgo, que Kant encarece en su pintura de la república, produce sin más el efecto tiránico del cual quiso huir el súbdito de Königsberg al reproducir con mimética precisión el contexto prusiano. República implicaba un orden de cosas articulado en torno a la existencia de un pueblo soberano y a la división de poderes, ${ }^{50}$ en la cual dicho pueblo era titular del legislativo o supremo. Pero república, en Kant, es algo más, vale decir: mucho menos. Nos enteramos ahora de que el concepto a priori de república distingue entre formas de gobierno -las tres clásicas, más o menos reconocidas en la época moderna ${ }^{51} \mathrm{y}$ basándose en el mismo criterio del número de personas depositarias del poder soberano- y ejercicio del poder, el cual puede ser republicano o despótico.

Eso significa, por abreviar, que una monarquía puede ser republicana, y que la sola condición para ello es que el rey use su poder como si éste derivara del contrato originario. Es decir, como si el rey sólo fuera el usufructuario, el representante hobbesiano de la soberanía popular, para lo cual lo tiene fácil: ante cada guerra debe preguntarse tan sólo si el pueblo, el autor que sufre, en sus carnes y su hacienda, las más graves consecuencias, la emprendería o no.

Naturalmente, y como en Hobbes, si el actor se preocupa más por su gloria personal que por la salvación de quien contractualmente le cedió el poder, éste, el pueblo, no puede oponer ningún "derecho coactivo" contra él, sino únicamente obedecer. ${ }^{52}$ En los hechos, por tanto, que el rey haga cuanto le venga en gana, abusar arbitrariamente de su depósito de soberanía, pero haciendo como si gobernara en nombre del pueblo es lo que Kant designa como ejercicio republicano del poder. ¿Qué monarca en su sano juicio no se declarará en tal caso republicano ${ }^{53}$

\footnotetext{
${ }^{50}$ Kant, Immanuel, Ensayos sobre la paz, el progreso y el ideal cosmopolita, Madrid, Cátedra, 2009, p. 151...

${ }^{51}$ Salvo preclaras excepciones, como Maquiavelo o Montesquieu.

${ }^{52}$ Y pensar que era contra Hobbes contra quien Kant había escrito la segunda parte de su Sobre el dicho común, tan sólo para reivindicar, frente al genial teórico inglés, la libertad de pensamiento (del filósofo y su camarilla, en realidad) como seña de identidad de la libertad.

${ }^{53}$ La sinrazón de un soberano legibus solutus aumenta cuando se recuerda que la elección del Herr, del "señor",
} 
Una federación de repúblicas así era el segundo paso en la escala de la paz. La marcha atrás que va marcando el paso kantiano en el grado de unión exigido a los Estados que han de constituirla va desde la añorada república mundial hasta un descolorido congreso de Estados. Ello refleja el pesimismo kantiano en relación con el grado de responsabilidad que los Estados se manifiestan dispuestos a asumir por una alianza común. Por ende, se muestran en pro del objetivo común de obtener y preservar sine die la paz mundial. ${ }^{54}$ Ahora bien, esa decadencia en la fe en los Estados actuales, ¿no es inmediatamente extrapolable al modelo construido según el concepto racional a priori de paz?

Prescindamos empero de tan fatales insuficiencias y demos crédito a Kant cuando anuda la república y su firme unión a la paz. Prescindamos asimismo de que cuando se habla del mundo se está hablando de ese trozo de mundo que es Europa, por entonces la mayor potencia mundial y hoy un don nadie en la convulsa sociedad internacional. ¿Sería la paz realmente la consecuencia inmediata de ambos factores? Peor aún: ¿es deseable que lo sea?

El defecto está, una vez más, en la teoría. Esa teoría que también aquí se quiere unir férreamente con la práctica no da cuenta de cómo surgen, se mantienen y decaen las potencias. Tampoco da cuenta del papel que juegan los Estados satélites o esos otros intermedios, cuyo simple ascenso pone en cuestión la jerarquía del statu quo. Tampoco del papel que las diversas asociaciones estatales juegan con sus miembros, así como las relaciones de los mismos. Esta teoría tampoco considera el lugar sagrado que ocupan las circunstancias de guerra o paz en general.

Para todo ello la experiencia habría suministrado material de importancia capital, pero es justamente la experiencia aquello cuya validez se niega en una teoría que parte de conceptos a priori, deducidos por la razón a partir de una necesidad creada por ella misma. Además, en ella se niegan determinadas bases históricas, apenas se fundan en la historia real, de modo que ciertos fines acarreados por una ingenua "buena fe", como la propia paz, aparecen reclamados por una férrea lógica.

Insistamos: ¿es posible, o aun deseable, una paz que requiera la federación mundial de las repúblicas? ¿Es acaso posible la transformación de todos los Es-

constituia el mayor problema para el establecimiento de una sociedad civil republicana. Lo era justamente porque era un ser humano que poseia todos los defectos de sus congéneres. No obstante, antes en 1784, como ahora, once años después, se le sigue atribuyendo un poder absoluto sobre sus súbditos: era el lobo de Hobbes campando a sus anchas en la sociedad.

${ }^{54}$ HeRMOSA, Antonio, "La concepción kantiana de las relaciones internacionales", Revista de Estudios Políticos, núm. 64, 1989, p. 182. 
tados mundiales en repúblicas? Más aún: ¿es acaso posible la transformación de todas las asociaciones o agrupamientos humanos en Estados? Dejemos que la ilusión nos convenza y digamos que sí. ¿Qué ocurriría en el interim? Las guerras, que inevitablemente tendrían lugar, ¿no verían implicadas también a algunas democracias?, ¿no afectarían a sus constituciones, a la visión del mundo de sus habitantes si se prolongan en el tiempo o se producen genocidios u otros crímenes contra la humanidad?

Las democracias son, en el mejor de los casos, un seguro de paz frente a otras democracias, no frente a los otros regimenes. Pero las autocracias no necesariamente son causas de amenaza contra la paz mundial, aunque haya innumerables tiranos que sí lo son, sobre todo en el mundo actual. Un personaje como el presidente sirio, en efecto, es hoy tirano a escala universal porque su política interna está sirviendo como detonante de una próxima guerra regional, cuyos efectos serían devastadores para la convivencia internacional.

Aun así, no todas las tiranías patrocinan la guerra: ¿se les invade también para acelerar su conversión en "repúblicas”, es decir, en nombre de la paz? Una paz hecha de pequeñas o grandes paces que cubren una gran superficie del mapa mundial, pero que coexisten con guerras locales que aquí o allá lo salpican, es el máximo de paz alcanzable por ahora. Y es, sin duda, lo que también se deriva del proyecto kantiano, toda vez que en él sólo la totalidad de los Estados republicanos deviene en condición sine qua non para que la paz mundial se convierta en un ser real. Ello toda vez que se asiente en una visión realista de la naturaleza humana, la cual impide cualquier exceso racional, incluida la utopía de una eterna paz universal. ${ }^{55}$

La conclusión, por tanto, es que en el ámbito de la política internacional debemos separar el problema de la paz del problema de la justicia o de la libertad. Con la política jurídica, debemos considerar el orden democrático (republicano) como inmune a la guerra. Con la política intelectual, debemos de considerar que la teoría se prolonga naturalmente en la práctica, según Kant entiende. La paz es un problema mundial, sí, pero no admite una única solución general deducible a priori de una razón universal.

\footnotetext{
${ }^{55}$ No procederemos en nuestra exposición a la crítica del derecho cosmopolita, pese a que la afirmación del Besuchsrecht que implica no funciona siempre ni en la propia casa de uno: en la familiar, no en la nacional. Con todo, la crítica kantiana al comportamiento del visitante europeo, de los "comerciantes" en especial, a tierras lejanas en aras de su interés es radical: "produce espanto", sencillamente. Kant, Immanuel, Ensayos sobre la paz, el progreso y el ideal cosmopolita, Madrid, Cátedra, 2009, p. 158).
} 
Sobre la paz perpetua continúa en realidad la cuestión planteada en Sobre el dicho común acerca de la unidad entre la teoría y la praxis, pero alza la mira hasta una perspectiva en la cual se divisa el entero campo de la razón práctica. Si en esta obra Kant aspiraba a demostrar taxativamente el vínculo que, a través del concepto de deber, une en la moral por un lado y en el derecho por otro teoría y práctica, en aquélla aspira al más difícil todavía: demostrar la unidad entre la moral como teoría que, por medio del derecho, tiene su práctica en la política.

El concepto de deber ahora trasciende los confines internos de la moral y enlaza las tres ramas constitutivas del derecho público. ¿Cómo es posible dicha unidad? Máxime cuando la maldad humana no cesa de burlarse de la misma, degradando la moral a burda teoría, y cuando el soberano, "moralista práctico" al decir de Kant, sólo acude a la expresión menor de la moral, la Klugheit o prudencia, cuando le da por servirse de ella. ${ }^{56}$

El secreto queda rápidamente propalado en el quehacer del "político moralista”, quien confía en que incluso del leño torcido de la condición humana quepa extraer acciones suficientemente rectas. Éste devuelve a la esperanza su poder sobre el futuro al proponerse como objetivo recomponer las insuficiencias actualmente perceptibles sea en la constitución de los Estados, sea en sus mutuas relaciones. Ello significa el dilema de todo hombre de Estado: si cifrar su actividad en el principio material, o fin del arbitrio, de la razón práctica, para el que todos los problemas políticos no son sino problemas técnicos; o bien, en su principio formal, que daría a su acción el tinte de la acción universalizable.

El hombre de Estado se decantaría por éste, porque es así como sus máximas se basarían en el concepto puro de deber, en lugar de hacerlo en el bienestar o la felicidad del Estado que gobierna. Nada, pues, ha cambiado, según cabe apreciar, en el razonamiento general pese al cambio de contexto.

Kant ejemplariza la preconizada unidad del siguiente modo: "La política dice: 'Sed astutos como la serpiente'. La moral añade (como condición limitativa): ‘y cándidos como las palomas”. ${ }^{57}$ Redundando en su convicción, Kant sentencia que ambos preceptos caben en uno. ¿Y qué observamos aquí? Pues, sencillamente, a Kant como reencarnación de Maquiavelo. Es verdad que habla de la zorra y no del león, pero ¿serviría de algo en política ser zorra sin ser también león?,

\footnotetext{
${ }^{56}$ Su acción, aun sin pretenderlo, se basan en tres máximas ya demasiado conocidas: Fac et excusa, Si feciste, nega y Divide et impera. Es la trilogía falsamente moral del político prudente, mediante las cuales éste se complace en la astucia del mal y se revela incapaz de derrotarla trascendiéndolo. Para una valoración general del significado de la prudencia en Kant, véase Reinhard, BRAnd, "Reflexiones acerca de la prudencia en Kant", Isegoría, 2004, pp. 7-40. ${ }^{57}$ Kant, Immanuel, Ensayos sobre la paz, el progreso y el ideal cosmopolita, Madrid, Cátedra, 2009. Para todo lo que venimos analizando, véase entero el Apéndice I, pp. 170-182. Esta última frase se encuentra en la p. 170.
} 
¿serviría engañar sin fuerza por si se descubre el engaño ${ }^{58} \mathrm{Y}$, por lo demás, ¿qué es el engaño, la mentira de Platón, sino una forma de fuerza no violenta? Es la puerta de atrás por la cual la fuerza puede entrar en la plaza pública $\mathrm{y}$, una vez allí, revelarse sin el embozo que la recubrió al cruzar.

Es verdad que también hay que ser paloma, pero una vez presente la zorra en el gallinero, ¿quién puede asegurar que la zorra, habiendo devorado gallinas, no se pida alguna paloma de postre? Supongamos que con las gallinas haya satisfecho plenamente su apetito y que la paloma pueda pasearse orgullosa a su lado: seguimos sin salir de Maquiavelo, pues también él se quedó sin enfrentar estructuralmente política y ética. Más aún, las hizo cooperar ordinariamente, sólo que Maquiavelo, que de política entendía, sabía una cosa que no parece saber Kant: si hay mal en el mundo no es porque la razón no consiga ilustrar a Júpiter, el dios-término del poder y le arrebate su destino de violencia. Es decir, que el mal -y esto Kant lo sabía con demasiada certeza antes de escribir estas palabras- pertenece a la condición humana y es inherente a la misma. Pese a ello, una determinada organización de la sociedad que favorezca sus cualidades pro-sociales permite no sólo la convivencia, sino añadir libertad a la misma.

En otras palabras, el mal no es un hecho intelectual; no se extiende por la sociedad a causa de un defecto en el ejercicio del imperio de la razón, sino que hay una voluntad detrás que lo desea y aun racionaliza. Maquiavelo, profesor en la materia, tensó por eso la cuestión de las relaciones entre ética y política al declarar que, en ocasiones, la salvación de una sociedad depende de que la política se salga de su curso ordinario y persiga la moral o la religión, porque de no hacerlo la destrucción de aquélla quedaría garantizada.

Es lo que Kant no supo o no quiso ver: que rendir tributo a la paloma no sólo puede dar pábulo a la caza de la zorra -y del león al acecho bajo su sombra-, sino que es un acto de culto por el cual se procede al sacrificio de una sociedad, a su destrucción. Son precisas, en suma, más y mejores teorías, y menos unidad sistemática entre ellas, que la preconizada por Kant para alcanzar y preservar la paz en aras de la seguridad internacional.

\footnotetext{
${ }^{58}$ Ya Tácito nos había enseñado que "ninguna cosa es tan inestable e insegura como la fama de poder no apoyada en la propia fuerza". TÁcito, Anales, Madrid, Gredos, 2001. Por cierto, Maquiavelo cita dicha frase en el capítulo 13 de su Príncipe.
} 


\section{Bibliografía}

Demóstenes, Discursos políticos, Barcelona, Ediciones Iberia, 1969.

Grocio, Hugo, De la libertad de los mares, Madrid, Instituto de Estudios Políticos, 1979.

Hermosa, Antonio, "La concepción kantiana de las relaciones internacionales”, Revista de Estudios Politicos, núm. 64, 1989.

Hesiodo, Obras y fragmentos, Madrid, Gredos, 2000.

Hume, DAVID, Ensayos morales, politicos y literarios, Madrid, Trotta, 2011.

Isócrates, Discursos, Madrid, Gredos, 2002.

Kant, Immanuel, Schriften zur Anthropologie, Geschichtsphilosophie, Politik und Pädagogik, Frankfurt am Main, Suhrkamp, 1978.

Kant, Immanuel, Ensayos sobre la paz, el progreso y el ideal cosmopolita, Madrid, Cátedra, 2009.

Loewenstein, KarL, Teoría de la Constitución, Barcelona, Ariel, 1976.

Marco Aurelio, Meditaciones, Madrid, Gredos, 2001.

Peñas, Francisco JaVier, Hermanos y enemigos. Liberalismo y relaciones internacionales, Madrid, Universidad Autónoma de Madrid, 2003.

PíndARO, Obras y fragmentos, Madrid, Gredos, 2002.

REINHARD, BRANDT, "Reflexiones acerca de la prudencia en Kant”, Isegoría, 2004.

RIDDER, Helmut, "La guerra y el derecho de guerra en el derecho internacional y en la doctrina internacionalista”, Revista de Estudios Politicos, núm. 92, 1957.

Spinoza, Baruch, Tratado Teológico-Político, Madrid, Alianza, 1986.

TÁcıтo, Anales, Madrid, Gredos, 2001.

Tiтo Livio, Historia de Roma, Madrid, Gredos, 2001.

Tucídides, Historia de la Guerra del Peloponeso, Madrid, Tecnos, 2000.

VITORIA DE, FRANCISCO, Relección primera sobre los indios recientemente descubiertos, Madrid, Tecnos, 1998. 